\title{
Thermophysical and thermochemical properties of new thermal barrier materials based on $\mathrm{Dy}_{2} \mathrm{O}_{3}-\mathrm{Y}_{2} \mathrm{O}_{3}$ co-doped zirconia Liu Qu ${ }^{1}$ and Kwang-Leong Choy ${ }^{{ }^{*}}$
}

${ }^{1}$ UCL Institute for Materials Discovery, University College London, 20 Gordon Street, London WC1H 0AJ, United Kingdom

*Corresponding author. Tel/fax: +44 2076793855

E-mail address: k.choy@ucl.ac.uk (Kwang-Leong Choy)

\begin{abstract}
$\mathrm{Dy}_{2} \mathrm{O}_{3}-\mathrm{Y}_{2} \mathrm{O}_{3}$ co-doped $\mathrm{ZrO}_{2}$ would potentially give lower thermal conductivity and higher coefficient of thermal expansion, which is a promising ceramic thermal barrier coating material for aero gas turbines and high temperature applications in metallurgical and chemical industry. In this study, $\mathrm{Dy}_{2} \mathrm{O}_{3}-\mathrm{Y}_{2} \mathrm{O}_{3}$ co-doped $\mathrm{ZrO}_{2}$ ceramics were prepared using solid state reaction methods. $\mathrm{Dy}_{0.5} \mathrm{Zr}_{0.5} \mathrm{O}_{1.75}$ and $\mathrm{Dy}_{0.25} \mathrm{Y}_{0.25} \mathrm{Zr}_{0.5} \mathrm{O}_{1.75}$ consist of pure cubic fluorite phase, whereas both $\mathrm{Dy}_{0.06} \mathrm{Y}_{0.072} \mathrm{Zr}_{0.868} \mathrm{O}_{1.934}$ and $D_{0.02} \mathrm{Y}_{0.075} \mathrm{Zr}_{0.905} \mathrm{O}_{1.953}$ have tetragonal and cubic composite phases. The influence of the chemical composition on coefficient of thermal expansion (CTE) and the thermal conductivity was investigated by varying the content of rare earth dopant. $\mathrm{Dy}_{0.06} \mathrm{Y}_{0.072} \mathrm{Zr}_{0.868} \mathrm{O}_{1.934}$ exhibited a lower thermal conductivity and higher coefficient of thermal expansion as compared with standard 8 wt. $\% \mathrm{Y}_{2} \mathrm{O}_{3}$ stabilized $\mathrm{ZrO}_{2}$ which is used in conventional thermal barrier coatings. The compatibility between the thermally grown oxide that consists of $\mathrm{Al}_{2} \mathrm{O}_{3}$ and the new compositions is critical to ensure the durability of thermal barrier coatings. Hence, the compatibility between $\mathrm{Al}_{2} \mathrm{O}_{3}$ and $\mathrm{Dy}_{2} \mathrm{O}_{3}-\mathrm{Y}_{2} \mathrm{O}_{3}$ codoped YSZ was investigated by mixing two types of powders and eventually sintered at $1300^{\circ} \mathrm{C}$. Dy $0.06 \mathrm{Y}_{0.072} \mathrm{Zr}_{0.868} \mathrm{O}_{1.934}$ is compatible with $\mathrm{Al}_{2} \mathrm{O}_{3}$, whereas $\mathrm{YAlO}_{3}$ and $\mathrm{Dy}_{3} \mathrm{Al}_{2}\left(\mathrm{AlO}_{4}\right)_{3}$ were formed when $\mathrm{Dy}_{0.25} \mathrm{Y}_{0.25} \mathrm{Zr}_{0.5} \mathrm{O}_{1.75}$ and $\mathrm{Al}_{2} \mathrm{O}_{3}$ were mixed and sintered.
\end{abstract}

Keywords: New thermal barrier materials; rare earth doped ceramics; thermal conductivity; thermal expansion coefficient; thermochemical compatibility

\section{Introduction}

$\mathrm{ZrO}_{2}$ partially stabilized with 6-8 wt\% $\mathrm{Y}_{2} \mathrm{O}_{3}$ (i.e. $3-4.5 \mathrm{~mol} \% \quad \mathrm{Y}_{2} \mathrm{O}_{3}$ partially stabilized $\mathrm{ZrO}_{2}$ ) is commonly used as a thermal barrier coating material for gas turbine components to protect them from high operating temperatures and hot corrosion. Thermal barrier coatings (TBCs) are a complex system and the durability and engine efficiency are critical factors to be considered in the development of new TBCs [1]. The t'-tetragonal 6-8 wt\% YSZ would transform into tetragonal and cubic phases, and further into monoclinic phase, bringing about thermal mismatch between the bond coat and the top coat at around $1200^{\circ} \mathrm{C}[2]$. Furthermore, the formation of cracks within TBCs can reduce the life time 
Thermophysical and thermochemical properties of new thermal barrier materials based on $\mathrm{Dy}_{2} \mathrm{O}_{3}-$ $\mathrm{Y}_{2} \mathrm{O}_{3}$ co-doped zirconia

of the TBCs and increase the cost for the whole process in industry [3]. Rare earth oxide doped $\mathrm{ZrO}_{2}$ has been considered as a substitute for the conventional 6-8 wt\% YSZ because of the potential improved material properties such as reduced thermal conductivity and enhanced phase stability at much higher temperatures. Various types of new TBC materials have been developed, such as $\mathrm{ABO}_{3}$ perovskite structure [4], $\mathrm{A}_{2} \mathrm{Zr}_{2} \mathrm{O}_{7}$ pyrochlore structure [5] and $\mathrm{A}_{2} \mathrm{Zr}_{2} \mathrm{O}_{7}$ defect fluorite structure [6]. Although rare earth oxides such as $\mathrm{La}_{2} \mathrm{O}_{3}$ and $\mathrm{Sm}_{2} \mathrm{O}_{3}$ have been used as dopants to reduce the thermal conductivity and enhance the operating temperature of the engine, limited studies have been conducted on $\mathrm{Dy}_{2} \mathrm{O}_{3}$ as a dopant $[5,7]$. $\mathrm{Dy}_{2} \mathrm{O}_{3}$ doped $\mathrm{ZrO}_{2}$ gives a stable fluorite phase between room temperature and high temperature $\left(2900^{\circ} \mathrm{C}\right)$ in a relatively wide composition [8]. 5-20\% $\mathrm{Dy}_{2} \mathrm{O}_{3}$ doped $5 Y S Z$ have been investigated by Wang, summarizing that the $10 \%$ Dy and $\mathrm{Y}$ co-doped $\mathrm{ZrO}_{2}$ coatings gave a higher resistance to heat transfer. Air plasma spraying method was used in Wang's work and the obtained thermal conductivity was around $0.6-0.75 \mathrm{~W} / \mathrm{mK}$. Thermal barrier coating deposited by plasma spray method exhibits a typical thermal conductivity of $0.8-1.7 \mathrm{~W} / \mathrm{mK}$, and using Electron Beam Physical Vapor Deposition (EBPVD) it has a thermal conductivity of 1.5-2 W/mK [1].

A variety of methods can be used to fabricate the high temperature ceramic coatings including the commercial EBPVD and Plasma Spray (PS) methods, Chemical Vapor Deposition (CVD) method [9], Electrostatic Spray-Assisted Vapour Deposition (ESAVD) method [10], etc. Solid state method and chemical/liquid route have also been widely used to produce 6-8 wt\% YSZ bulk samples for mechanical, chemical and physical properties investigation. This paper highlights the development of new thermal barrier materials based on $\mathrm{Dy}_{2} \mathrm{O}_{3}-\mathrm{Y}_{2} \mathrm{O}_{3}$ co-doped $\mathrm{ZrO}_{2}$ and investigates their thermophysical properties as well as their thermochemical stability. In order to conduct this study, $\mathrm{Dy}_{2} \mathrm{O}_{3}-\mathrm{Y}_{2} \mathrm{O}_{3}$ co-doped $\mathrm{ZrO}_{2}$ was fabricated using a solid state reaction method. The thermochemical compatibility between the thermally grown oxide layer which consisting of $\mathrm{Al}_{2} \mathrm{O}_{3}$ and new thermal barrier materials was investigated. In addition, thermophysical and thermochemical properties such as thermal conductivity and CTE were also being characterized. The effects of co-dopants $\mathrm{Dy}_{2} \mathrm{O}_{3}-\mathrm{Y}_{2} \mathrm{O}_{3}$ on these properties were established.

\section{Experimental}

$\mathrm{ZrO}_{2}$ powders (Sigma-Aldrich), $\mathrm{Y}_{2} \mathrm{O}_{3}$ powders (Alfa Aesar, 99.99\%), $\mathrm{Dy}_{2} \mathrm{O}_{3}$ powders (Advanced Materials Resources) and $\mathrm{ZrO}_{2}$ partially stabilized with $4 \mathrm{~mol} \% \mathrm{Y}_{2} \mathrm{O}_{3}$ [4YSZ, $\mathrm{Zr}_{0.923} \mathrm{Y}_{0.077} \mathrm{O}_{1.962}$, (Tosoh Corporation)] were used as the starting materials. The Dy $\mathrm{D}_{0.5} \mathrm{Zr}_{0.5} \mathrm{O}_{1.75}$ [DZ], Dy $0.25 \mathrm{Y}_{0.25} \mathrm{Zr}_{0.5} \mathrm{O}_{1.75}$

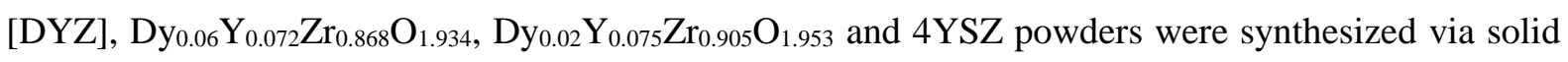
state reaction. $\mathrm{Dy}_{0.5} \mathrm{Zr}_{0.5} \mathrm{O}_{1.75}$ was prepared by mixing $\mathrm{Dy}_{2} \mathrm{O}_{3}$ and $\mathrm{ZrO}_{2}$ powders with a molar ratio of 1:2 in distilled water and $3 \mathrm{wt} . \%$ organic binder and $3 \mathrm{wt} . \%$ organic dispersant. The solution was subsequently stirred for $30 \mathrm{~min}$. Similarly, $\mathrm{Dy}_{0.25} \mathrm{Y}_{0.25} \mathrm{Zr}_{0.5} \mathrm{O}_{1.75}$ was prepared by mixing $\mathrm{Dy}_{2} \mathrm{O}_{3}, \mathrm{Y}_{2} \mathrm{O}_{3}$ and $\mathrm{ZrO}_{2}$ powders with a molar ratio of 1:1:4 in distilled water as well as $3 \mathrm{wt} . \%$ organic binder and 3 wt.\% organic dispersant. For $\mathrm{Dy}_{0.02} \mathrm{Y}_{0.075} \mathrm{Zr}_{0.905} \mathrm{O}_{1.953}$ and $\mathrm{Dy}_{0.06} \mathrm{Y}_{0.072} \mathrm{Zr}_{0.868} \mathrm{O}_{1.934}$ powders, $\mathrm{Dy}_{2} \mathrm{O}_{3}$ and 
YSZ were mixed with 3 wt.\% organic binder and 3 wt.\% organic dispersant in distilled water, followed by 30 min stirring process. The molar ratio of $\mathrm{DyO}_{1.5}$ was $2 \%$ and $6 \%$, respectively. The standard 4YSZ powders were mixed with $3 \mathrm{wt} . \%$ organic binder and $3 \mathrm{wt} . \%$ organic dispersant in distilled water. After drying, the dried powders were ball milled for $8 \mathrm{~h}$ and compacted into pellets, followed by pressureless sintering at $1400^{\circ} \mathrm{C}$ with a heating rate of $7^{\circ} \mathrm{C} / \mathrm{min}$ in the air atmosphere. The typical sintering time was $6 \mathrm{~h}$, while the sintering time for DYZ and DZ was increased to $12 \mathrm{~h}$ and $18 \mathrm{~h}$ to investigate the thermal behaviour of the as-synthesized pellets.

The crystal structure of $\mathrm{Dy}_{2} \mathrm{O}_{3}-\mathrm{Y}_{2} \mathrm{O}_{3}$ co-doped $\mathrm{ZrO}_{2}$ was characterized using $\mathrm{X}$-ray diffractomer (Siemens D500, $\mathrm{Cu} \mathrm{K \alpha}$ radiation) and Raman spectroscopy (Olympus BX41, He-Ne laser source $632.8 \mathrm{~nm}$ ). The scanning step is $0.05^{\circ}$ and the time step is $2 \mathrm{~s}$. The tension of the generator is The surface morphology of the particle and pellets were examined by the scanning electron microscope (SEM, Phillips XL30 ESEM-FEG). Coefficient of thermal expansion was measured from $100^{\circ} \mathrm{C}$ to $1000^{\circ} \mathrm{C}$ at a heating rate of $5^{\circ} \mathrm{C} / \mathrm{min}$ using a Thermalmechanical Analyzer (TMA, TA Instruments, Q400). The thermal conductivity of the pellets was measured using a TCi thermal conductivity analyser (C-Therm) at room with a thermal paste (Wakefield 120). The relative density was determined by measuring the density of the pellet and calculating the theoretical density of each chemical composition. The bulk density was determined via measuring the weight and the volume of the pellet directly. The bulk thermal conductivity can be calculated based on the porosity and the measured thermal conductivity using equation (1),

$$
\kappa_{\text {dense }}=\kappa_{\text {measured }} \frac{1}{1-1.5 \varphi}
$$

where $\varphi$ is the porosity, $\kappa_{\text {measured }}$ is the measured thermal conductivity and $\kappa_{\text {dense }}$ is the thermal conductivity for the dense material (Schlichting, Padture et al. 2001). The calculation of dense thermal conductivity is based on certain approximations including the spherical pores incorporated into the homogeneous medium, the thermal conductivity for pores is infinite, overall thermal conductivity $\mathrm{k}$ of porous materials is a sum of phonon scattering $\mathrm{k}_{\mathrm{P}}$ and photon scattering $\mathrm{k}_{\mathrm{R}}$.

\section{Results and Discussion}

\section{(a) SEM}

The SEM images of co-doped $\mathrm{Dy}_{0.25} \mathrm{Y}_{0.25} \mathrm{Zr}_{0.5} \mathrm{O}_{1.75}$ [DYZ] and $\mathrm{Dy}_{0.5} \mathrm{Zr}_{0.5} \mathrm{O}_{1.75}$ [DZ] are shown in Figure 1 (a) and (b), respectively. The recrystallization region (i.e. circled area) in which open pores were closed due to the diffusion of ions, was higher within DZ pellets than that in DYZ pellets. Open pores were on the surface of both the pellets and the shape of these pores was more homogeneous on DYZ pellets than that on DZ pellets. Furthermore, from the surface morphology point of view, the DYZ pellet had more pores as compared with the DZ pellet. The open pore area on the surface of the DYZ pellet was $24.7 \% \pm 0.7 \%$ while it was $33.7 \% \pm 0.1 \%$ for the DZ pellet. 
Thermophysical and thermochemical properties of new thermal barrier materials based on $\mathrm{Dy}_{2} \mathrm{O}_{3}-$ $\mathrm{Y}_{2} \mathrm{O}_{3}$ co-doped zirconia

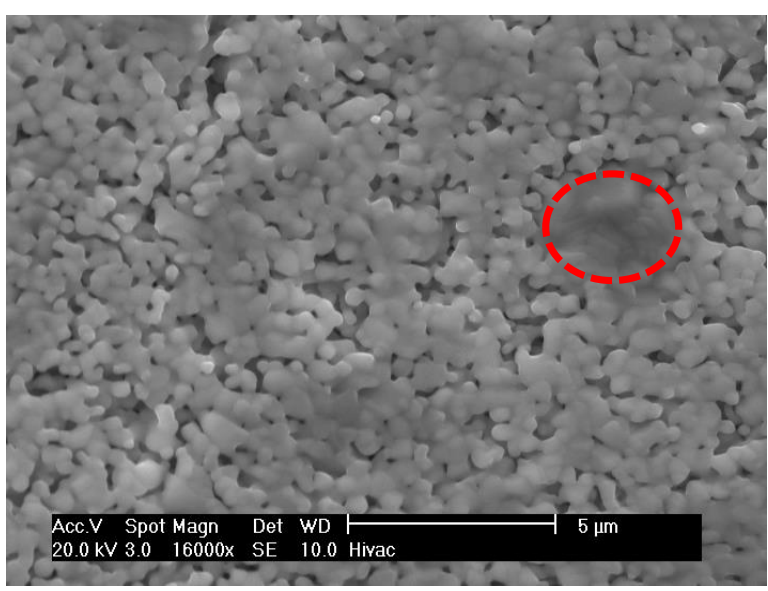

(a) DYZ pellet

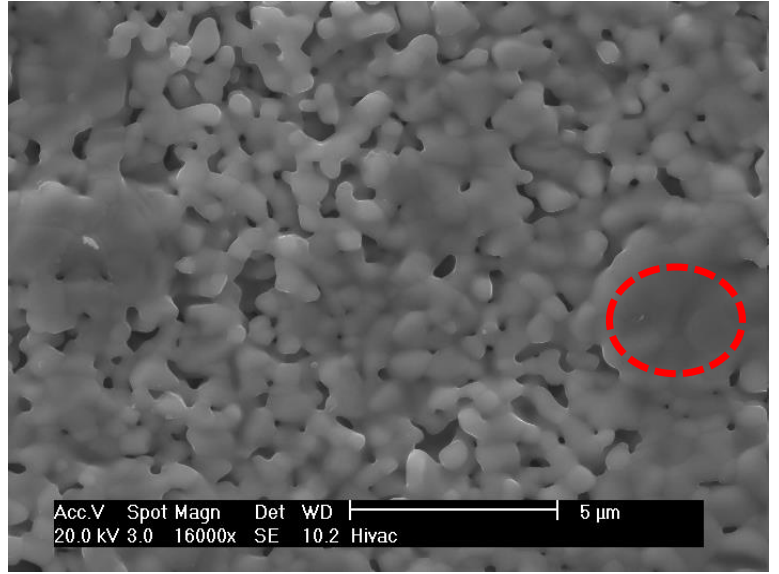

(b) DZ pellet

Figure 1 SEM images for: (a) DYZ pellet; (b) DZ pellet

\section{(b) XRD}

The sintered 4YSZ, $\mathrm{Dy}_{0.02} \mathrm{Y}_{0.075} \mathrm{Zr}_{0.905} \mathrm{O}_{1.953}$ and $\mathrm{Dy}_{0.06} \mathrm{Y}_{0.072} \mathrm{Zr}_{0.868} \mathrm{O}_{1.934}$ consisted of cubic and tetragonal phases. $\mathrm{Dy}_{0.25} \mathrm{Y}_{0.25} \mathrm{Zr}_{0.5} \mathrm{O}_{1.75}$ and $\mathrm{Dy}_{0.5} \mathrm{Zr}_{0.5} \mathrm{O}_{1.75}$ pellets exhibited pure cubic fluorite phase.

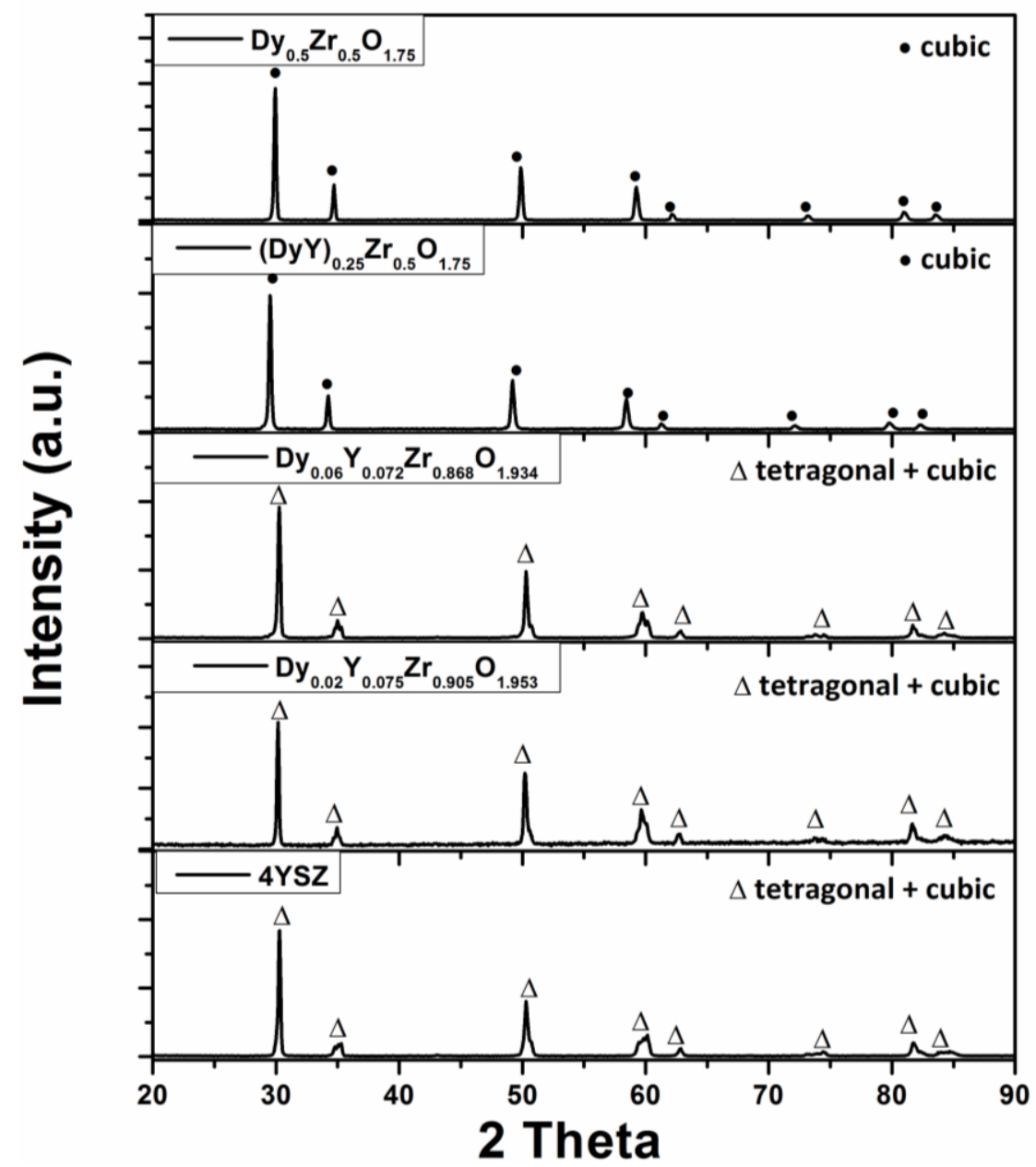

Figure 2 XRD patterns for $\mathrm{Dy}_{0.25} \mathrm{Y}_{0.25} \mathrm{Zr}_{0.5} \mathrm{O}_{1.75}, \mathrm{Dy}_{0.5} \mathrm{Zr}_{0.5} \mathrm{O}_{1.75}, \mathrm{Dy}_{0.02} \mathrm{Y}_{0.075} \mathrm{Zr}_{0.905} \mathrm{O}_{1.953}$ and $\mathrm{Dy}_{0.06} \mathrm{Y}_{0.072} \mathrm{Zr}_{0.868} \mathrm{O}_{1.934}$ 
The crystal size can be estimated based on line broadening using Scherrer equation (2),

$$
D_{X R D}=\lambda \frac{K}{B \cdot \cos \theta}
$$

where $\mathrm{D}$ is the dimension of crystalline, $\lambda$ is the wavelength $(\mathrm{Cu} \mathrm{K \alpha}), \Theta$ is the diffraction angle, $\mathrm{k}$ is the constant $(\sim 0.9)$ and $\mathrm{B}$ is the full-width half maximum (FWHM) [11]. The FWHM can be determined based on equation (3),

$$
B_{p}^{2}(2 \theta)=B_{h}^{2}(2 \theta)-B_{f}^{2}(2 \theta)
$$

where $B_{p}(2 \theta)$ is the true half maximum width, $B_{h}(2 \theta)$ is the measured half maximum width of the sample and $\mathrm{B}_{\mathrm{f}}(2 \Theta)$ the standard half maximum width [12]. The $\lambda_{\text {CuK } \alpha}=1.5406 \times 10^{-10} \mathrm{~m}$, and the standard material is $\mathrm{LaB}_{6} 300$.

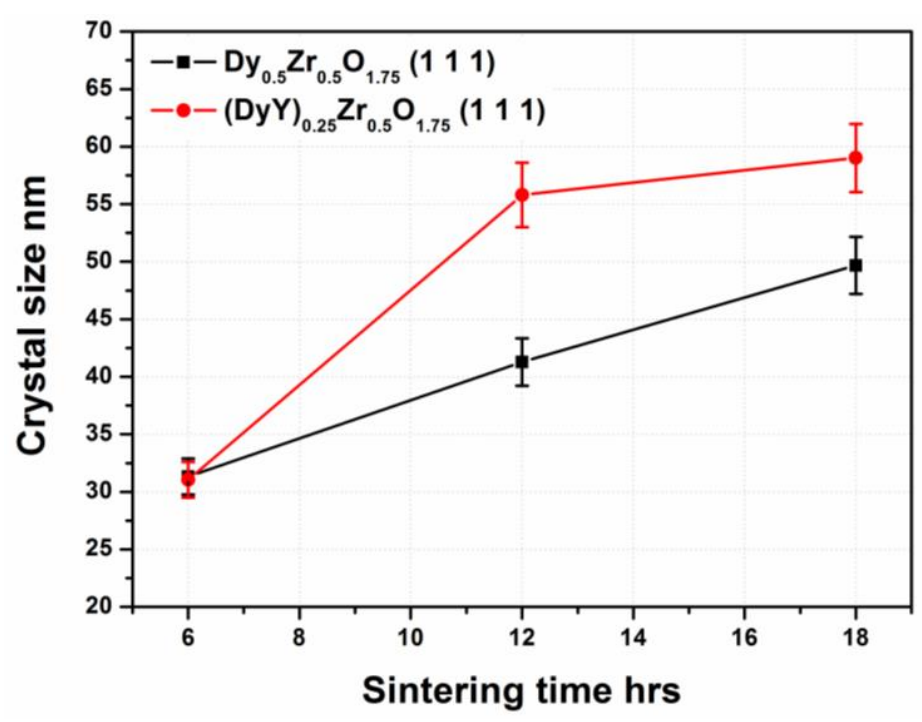

Figure 3 The crystal dimension of $\mathrm{Dy}_{0.5} \mathrm{Zr}_{0.5} \mathrm{O}_{1.75}$ and $\mathrm{Dy}_{0.25} \mathrm{Y}_{0.25} \mathrm{Zr}_{0.5} \mathrm{O}_{1.75}\left(\begin{array}{lll}1 & 1 & 1\end{array}\right)$

With the increase in sintering time, the crystal dimension of ( $\left.\begin{array}{lll}1 & 1 & 1\end{array}\right)$ for DZ pellets increased linearly and the crystal size for $\left(\begin{array}{lll}1 & 1 & 1\end{array}\right)$ DYZ pellets also increased. The grain growth due to sintering contributes to the decrease of grain boundaries, hence reducing the phonon scattering sources. As a result, the thermal conductivity of the pellets would increase with increasing sintering time. Moreover, the crystal size increment for DYZ pellets between $12 \mathrm{hrs}$ and $18 \mathrm{hrs}$ was $5.75 \%$ and for DZ was $20.32 \%$. During the long sintering time, the DYZ pellet exhibited a much lower increase in percentage as compared with DZ pellet. The reason for the difference of the grain growth between $12 \mathrm{~h}$ and $18 \mathrm{~h}$ for the two compositions can probably due to the different types of rare earth dopants and concentration in DYZ and DZ which exhibiting different migration processes at high temperature. Because the grain boundary growth is achieved via the diffusion of oxygen vacancies at the grain boundary, $\mathrm{Dy}^{3+}$ and $\mathrm{Y}^{3+}$ cations can diffuse at the grain boundary during the high-temperature calcination $[13,14]$. Moreover, the migration enthalpies for $\mathrm{Dy}^{3+}$ is higher that $\mathrm{Y}^{3+}$ in $\mathrm{ZrO}_{2}$ system at 
$1273 \mathrm{~K}$, indicating that during the initial period, in DYZ $\mathrm{Y}^{3+}$ cations diffuse while in DZ $\mathrm{Dy}^{3+}$ cations diffuse [15]. The crystal size for the $\mathrm{Dy}_{0.02} \mathrm{Y}_{0.075} \mathrm{Zr}_{0.905} \mathrm{O}_{1.953}, \mathrm{Dy}_{0.06} \mathrm{Y}_{0.072} \mathrm{Zr}_{0.868} \mathrm{O}_{1.934}$ and 4YSZ was not calculated due to the fact that the phases were tetragonal and cubic phases which cannot be determined using Scherrer equation.

\section{(c) Raman analysis}

The Raman spectrum for each composition is shown in Figure 4. Defect fluorites such as $\mathrm{Dy}_{0.5} \mathrm{Zr}_{0.5} \mathrm{O}_{1.75}$ and $\mathrm{Dy}_{0.25} \mathrm{Y}_{0.25} \mathrm{Zr}_{0.5} \mathrm{O}_{1.75}$ would give a single broad band Raman active mode. In Raman spectra, the broadband and low intensities are attributed to the defect fluorite in which the two cation sites are disordered and 1/8 of the anions are absent [16]. Such randomly distributed oxygen ions can bring about broad and continuum density of states [17]. Raman broadening can also be a result of structure disorder and the strain within a crystal [18]. Besides, there are six active Raman modes for tYSZ from 100 to $800 \mathrm{~cm}^{-1}$ and five active modes have been detected within 200 to $1000 \mathrm{~cm}^{-1}$ due to the Raman shift range limitation (Viazzi et al., 2008). $263 \mathrm{~cm}^{-1}$ is $\mathrm{E}_{\mathrm{g}}$ stretching mode; $321 \mathrm{~cm}^{-1}$ indicates $\mathrm{Zr}-\mathrm{O} \mathrm{B}_{1 \mathrm{~g}}$ bending mode; $467 \mathrm{~cm}^{-1}$ is $\mathrm{Zr}-\mathrm{O}$ stretching $\mathrm{E}_{\mathrm{g}}$ mode; $614 \mathrm{~cm}^{-1}$ is the symmetric O$\mathrm{Zr}-\mathrm{O} \mathrm{A}_{1 \mathrm{~g}}$ stretching mode; $641 \mathrm{~cm}^{-1}$ is the asymmetric O-Zr-O E $\mathrm{g}$ stretching mode [19].

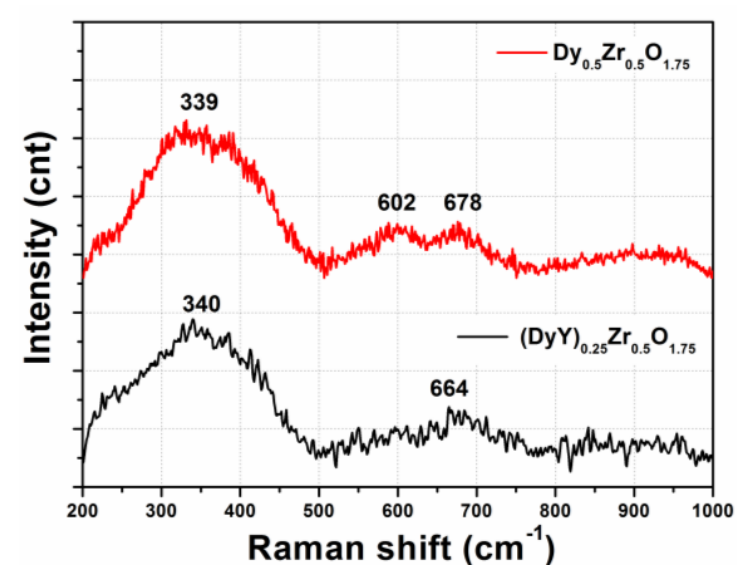

(a)

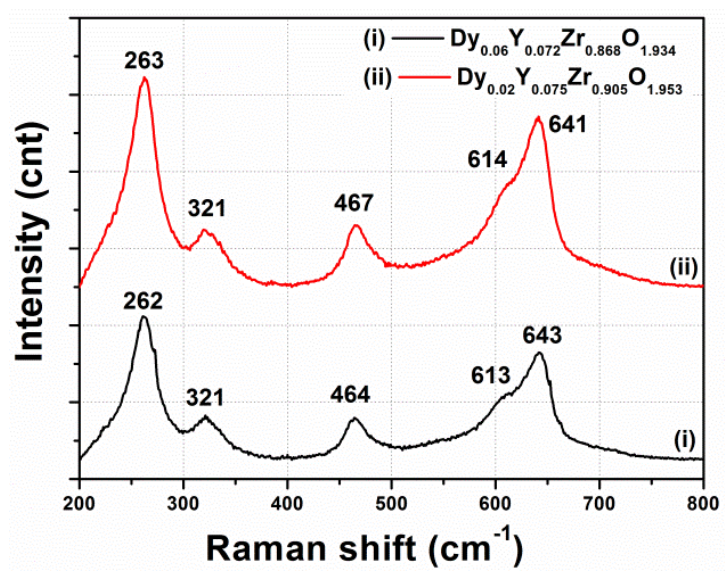

(b)

Figure 4 Raman spectrum for: (a) DZ and DYZ with 12h calcination; (b) Dy0.02 $\mathrm{Y}_{0.075} \mathrm{Zr}_{0.905} \mathrm{O}_{1.953}$ and $\mathrm{Dy}_{0.06} \mathrm{Y}_{0.072} \mathrm{Zr}_{0.868} \mathrm{O}_{1.934}$ with $6 \mathrm{~h}$ calcination

\section{(d) Thermal conductivity}

The thermal conductivities of the sintered pellets are shown in Figure 5. DYZ exhibited lower values for thermal conductivity than 4YSZ which is used in the conventional thermal barrier coatings. In addition, when the sintering time increased from $6 \mathrm{~h}$ to $12 \mathrm{~h}$, the thermal conductivity for DZ increased from $1.60 \mathrm{~W} / \mathrm{mK}$ to $2.40 \mathrm{~W} / \mathrm{mK}$, while for DYZ it increased from $1.14 \mathrm{~W} / \mathrm{mK}$ to $2.41 \mathrm{~W} / \mathrm{mK}$. 


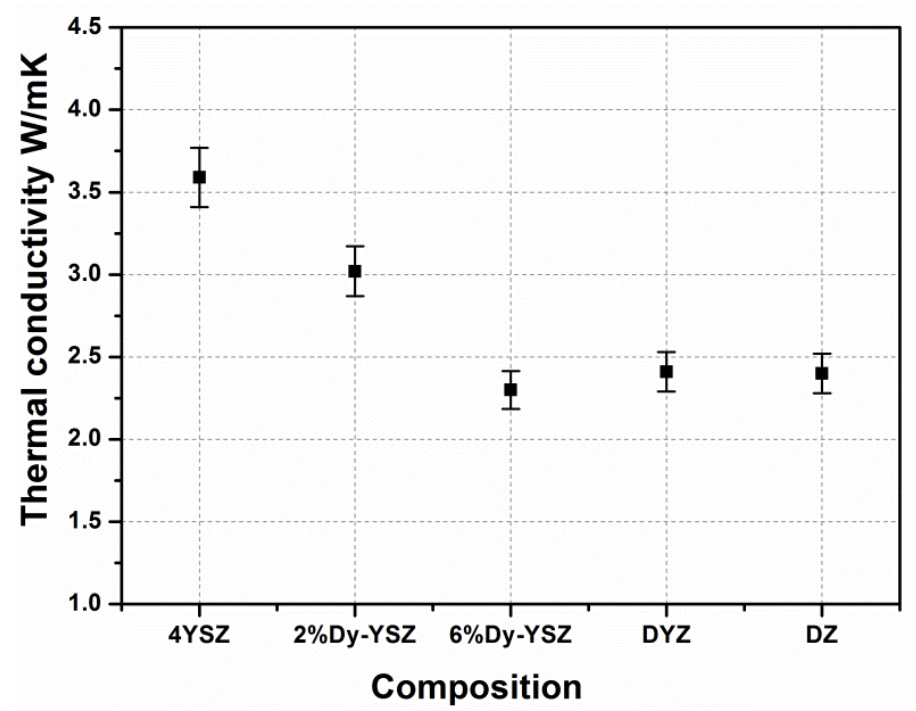

Figure 5 Thermal conductivity of various ceramic thermal barrier materials

The reasons could be that the addition of $\mathrm{Dy}_{2} \mathrm{O}_{3}$ can create more oxygen vacancies than YSZ [7]. In the solid solution, $\mathrm{Zr}^{4+}$ cation was substituted by $\mathrm{Dy}^{3+}$ and $\mathrm{Y}^{3+}$ cations with the incorporation of oxygen vacancies for charge compensation. For instance, based on the defect chemistry and KrogerVink notation,

$$
\mathrm{Dy}_{2} \mathrm{O}_{3} \stackrel{\mathrm{ZrO}_{2}}{\longrightarrow} 2 \mathrm{Dy}_{\mathrm{Zr}}^{\prime}+\mathrm{V}_{O}^{\prime \prime}+3 \mathrm{O}_{O}^{x}
$$

where $D y_{Z r}^{\prime}$ indicates $\mathrm{Dy}^{3+}$ cation taking the $\mathrm{Zr}^{4+}$ cation site with single negative charge, $V_{O}^{\prime \prime}$ is an +2 oxygen vacancy with double positive charges, and $O_{O}^{x}$ represents $\mathrm{O}^{2-}$ anion on the oxygen site with neutral charge [7]. The mean free path of phonons which can be significantly scattered by point defects such as lattice strain, cracks and porosity, is calculated using equation (5),

$$
\frac{1}{l_{p}}=\frac{a^{3}}{4 \pi v_{m}^{4}} \omega^{4} c\left(\frac{\Delta M}{M}\right)^{2}
$$

where $\mathrm{a}^{3}$ is the volume per atom, $\mathrm{c}$ is the defect concentration per atom, $\mathrm{v}_{\mathrm{m}}$ is the transverse wave speed, $\omega$ is the phonon frequency, $\mathrm{M}$ is the average mass of the host atom and $\Delta \mathrm{M}$ the mass differences between the substituted and the substituting atoms [20]. The atomic weight of Dy (162.5) is much heavier than that of $\mathrm{Y}$ (88.906) resulting in the higher scattering of phonon and photon in DYZ as compared with that in DZ due to the fact that the mean free path of the phonon is in proportion with the square of the atomic mass difference [21]. Furthermore, with increasing rare earth content, the thermal conductivity decreased and then remained relatively stable probably due to the different crystal structure and defect distribution. In defect fluorites DYZ and DZ, the phase consisted of pure cubic phase, whereas in $\mathrm{Dy}_{0.06} \mathrm{Y}_{0.072} \mathrm{Zr}_{0.868} \mathrm{O}_{1.934}$, both tetragonal and cubic existed. Although mass differences and defects such as oxygen vacancies in DYZ and DZ were higher than those in 
Thermophysical and thermochemical properties of new thermal barrier materials based on $\mathrm{Dy}_{2} \mathrm{O}_{3}-$ $\mathrm{Y}_{2} \mathrm{O}_{3}$ co-doped zirconia

$\mathrm{Dy}_{0.06} \mathrm{Y}_{0.072} \mathrm{Zr}_{0.868} \mathrm{O}_{1.934}$ because of the higher molar percentages, the overall thermal conductivities were comparable among fluorite $\mathrm{DYZ}$ and $\mathrm{DZ}$, tetragonal and cubic $\mathrm{Dy}_{0.06} \mathrm{Y}_{0.072} \mathrm{Zr}_{0.868} \mathrm{O}_{1.934}$.

\section{(e) Coefficient of thermal expansion}

The coefficient of thermal expansion (CTE) for each composition was measured from room temperatures to $1000^{\circ} \mathrm{C}$. The $\mathrm{Dy}_{2} \mathrm{O}_{3}-\mathrm{Y}_{2} \mathrm{O}_{3}$ co-doped $\mathrm{ZrO}_{2}$ exhibited enhanced CTE with the increase in the concentration of the dopant as compared with 4YSZ.

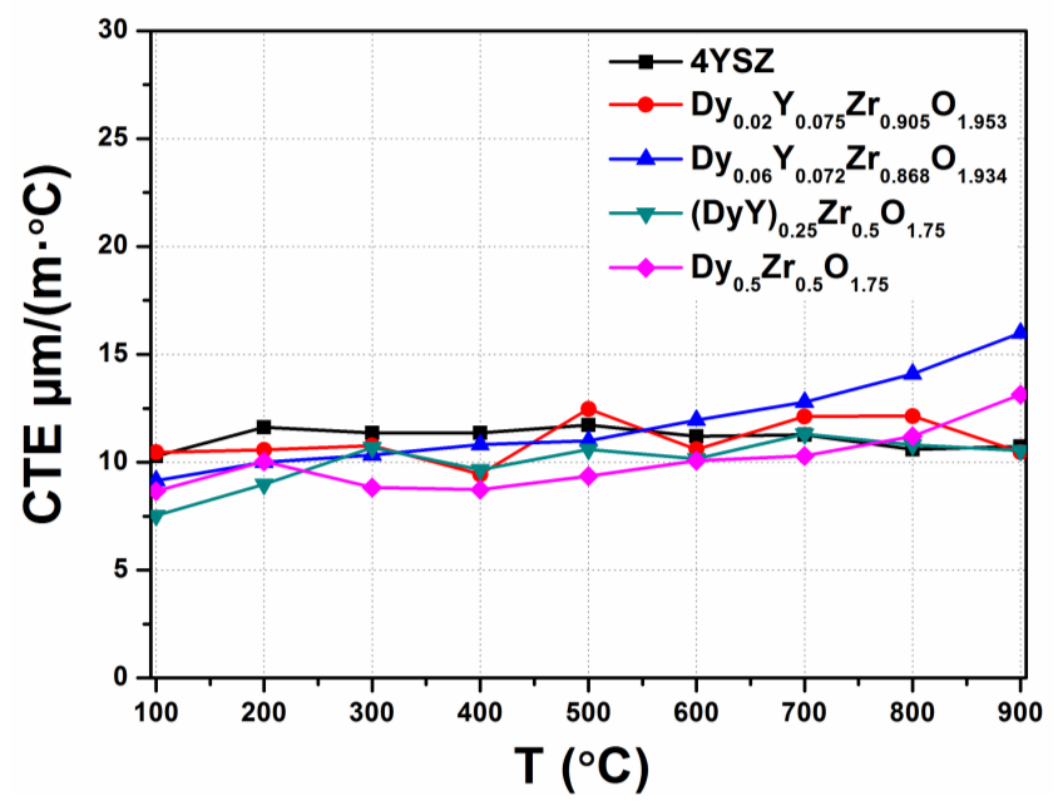

Figure 6 CTE for various ceramic thermal barrier materials from 100 to $1000^{\circ} \mathrm{C}$ (units of $\mathrm{CTE}$ refer to $10^{-6} /{ }^{\circ} \mathrm{C}$ )

In the high temperature range, with the increase in the concentration of the rare earth oxide dopant from $2 \%$ to $6 \%$, the CTE values increased continuously. The increased content in the dopants resulted in the increase of the concentration of oxygen vacancies and other defects in the YSZ lattice because of the valence difference between rare earth ions and zirconium ions [22]. Furthermore, it has been reported that for $\mathrm{A}_{2} \mathrm{Zr}_{2} \mathrm{O}_{7}$ pyrochlore and fluorite structure, $\mathrm{Zr}-\mathrm{O}$ bond is the most critical parameter influencing CTE after which A-O is the second most important factor while an O-O bond has little influence on the CTE and fluorite structure, which has a weaker $\mathrm{Zr}-\mathrm{O}$ bond and gives higher CTE than pyrochlore [23]. The presence of defects such as voids, debonding, grain boundary and cracks may weaken the atomic bond and thus can enhance the CTE values. Moreover, the CTE of rare earth doped $\mathrm{ZrO}_{2}$ increases with decreasing dopant radius [24], Dy ${ }^{3+}$ is one of the smallest rare earth ions and DYZ has the potential to exhibit a much lower CTE than 4YSZ. However, DZ exhibited higher CTE values than YSZ when temperature is high than $800^{\circ} \mathrm{C}$, while YSZ had higher CTE values than DYZ over $100-1000^{\circ} \mathrm{C}$. The reason can be due to the fact that DYZ and DZ exhibited cubic phase while 4YSZ had tetragonal and cubic phases which involving defects such as phase boundaries. These defects can further weaken the atomic bond and increase CTE. 


\section{(f) Thermochemical compatibility}

The phase composition of the sintered mixture of $\mathrm{Al}_{2} \mathrm{O}_{3}$ and $\mathrm{Dy}_{2} \mathrm{O}_{3}-\mathrm{Y}_{2} \mathrm{O}_{3}$ co-doped $\mathrm{ZrO}_{2}$ is shown in the XRD pattern. In the $\mathrm{DYZ}$ and $\mathrm{Al}_{2} \mathrm{O}_{3}$ mixture, there are new phases, $\mathrm{YAlO}_{3}$ and $\mathrm{Dy}_{3} \mathrm{Al}_{2}\left(\mathrm{AlO}_{4}\right)_{3}$, while in the $\mathrm{Al}_{2} \mathrm{O}_{3}$ and $\mathrm{Dy}_{0.06} \mathrm{Y}_{0.072} \mathrm{Zr}_{0.868} \mathrm{O}_{1.934}$ mixture, no any new phase has been detected.

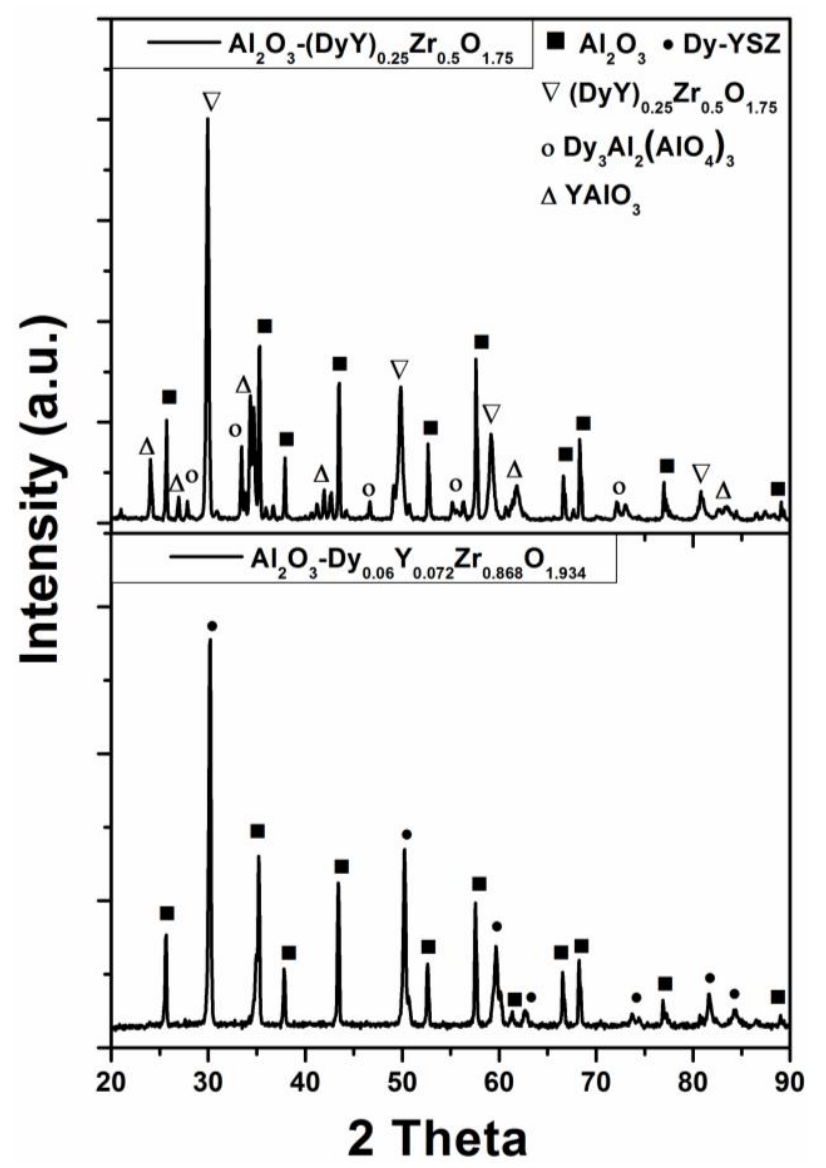

(a)

(b)

Figure 7 XRD pattern of the mixed powders of: (a) $\mathrm{Al}_{2} \mathrm{O}_{3}$ and (DyY) ${ }_{0.25} \mathrm{Zr}_{0.5} \mathrm{O}_{1.75}$; (b) $\mathrm{Al}_{2} \mathrm{O}_{3}$ and $\mathrm{Dy}_{0.06} \mathrm{Y}_{0.072} \mathrm{Zr}_{0.868} \mathrm{O}_{1.934}$

The compatibility between $\mathrm{Al}_{2} \mathrm{O}_{3}$ and $\mathrm{Dy}_{2} \mathrm{O}_{3}-\mathrm{Y}_{2} \mathrm{O}_{3}$ co-doped $\mathrm{ZrO}_{2}$ can be studied via sintering the mixture of a $50 \mathrm{wt} . \%$ of each type of powders. After $1400^{\circ} \mathrm{C} 8 \mathrm{~h}$ sintering, the DYZ powders reacted with $\mathrm{Al}_{2} \mathrm{O}_{3}, \mathrm{YAlO}_{3}$ and $\mathrm{Dy}_{3} \mathrm{Al}_{2}\left(\mathrm{AlO}_{4}\right)_{3}$ were formed while no new phases were detected in the mixture of $\mathrm{Al}_{2} \mathrm{O}_{3}$ and $\mathrm{Dy}_{0.06} \mathrm{Y}_{0.072} \mathrm{Zr}_{0.868} \mathrm{O}_{1.934}$ powders. This can be a result of higher driving forces of the interdiffusion of Dy ions into $\mathrm{Al}_{2} \mathrm{O}_{3}$ crystals when the content of rare earth oxides increased. From $1600^{\circ} \mathrm{C}$ onwards, $\mathrm{Dy}_{2} \mathrm{O}_{3}$ reacted with $\mathrm{Al}_{2} \mathrm{O}_{3}$ forming new solid state solutions with varied chemical compositions (Figure 8) [25]. In the solid state reaction, the reaction between $\mathrm{Al}_{2} \mathrm{O}_{3}$ and $\mathrm{Dy}_{2} \mathrm{O}_{3}-\mathrm{Y}_{2} \mathrm{O}_{3}$ co-doped $\mathrm{ZrO}_{2}$ depends on the diffusion of $\mathrm{Al}^{3+}$, $\mathrm{Dy}^{3+}$ and $\mathrm{Y}^{3+}$, which is controlled by a parabolic rate law [26],

$$
\frac{d x}{d t}=k \cdot x^{-1}
$$


where $\mathrm{x}$ is the amount of reaction, $\mathrm{t}$ is time and $\mathrm{k}$ is rate constant. With the increase of the thickness of the reaction layer between $\mathrm{Al}_{2} \mathrm{O}_{3}$ and $\mathrm{Dy}_{2} \mathrm{O}_{3}-\mathrm{Y}_{2} \mathrm{O}_{3}$ co-doped $\mathrm{ZrO}_{2}$, the reaction rates decreased. Other factors that influence the reaction rates include the surface area and the contact area between the solid oxide, the rate of nucleation of the new phase, and the diffusion rate of ions. Therefore, the reaction between $\mathrm{Al}_{2} \mathrm{O}_{3}$ and DYZ could occur readily, whereas $\mathrm{Dy}_{0.06} \mathrm{Y}_{0.072} \mathrm{Zr}_{0.868} \mathrm{O}_{1.934}$ is thermochemically stable with $\mathrm{Al}_{2} \mathrm{O}_{3}$. The solid state reaction is a slow process even at high temperatures because it involves the breaking of chemical bonds and the migration of ions, which requires sufficient thermal energy to allow the ions to diffuse through the lattice.

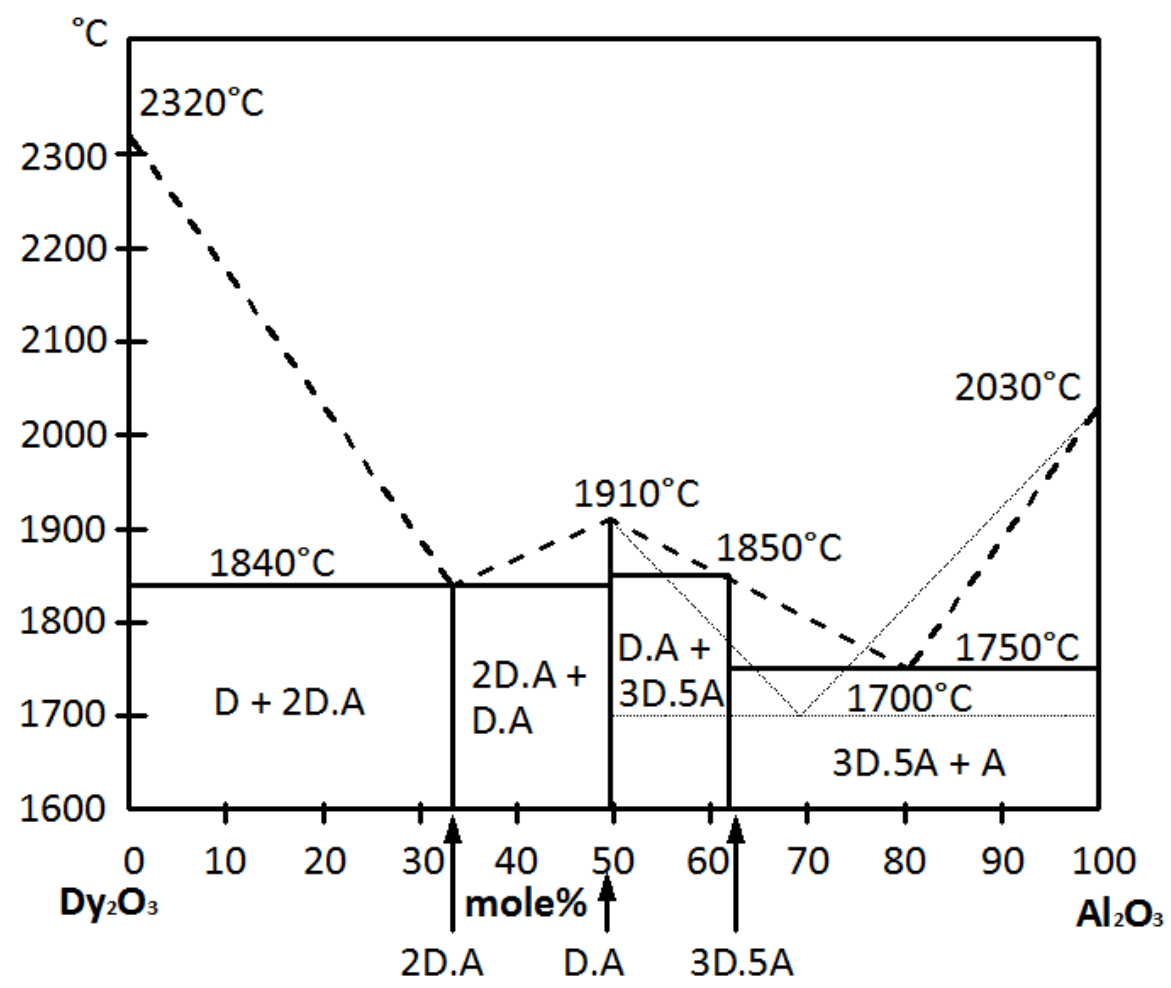

Figure 8 Binary phase diagram of $\mathrm{Dy}_{2} \mathrm{O}_{3}-\mathrm{Al}_{2} \mathrm{O}_{3}[25]$

Such new perovskite phase which has lower CTE as compared with t-YSZ can bring about thermal stress at the interfaces of TBCs at high temperatures and hence influence the performance of the new TBCs [27]. The compatibility between $\mathrm{Al}_{2} \mathrm{O}_{3}$ and $\mathrm{Dy}_{2} \mathrm{O}_{3}-\mathrm{Y}_{2} \mathrm{O}_{3}$ co-doped $\mathrm{ZrO}_{2}$ can be maintained when the content of oxide dopants $\left(\mathrm{DyO}_{1.5}\right.$ and $\left.\mathrm{YO}_{1.5}\right)$ reached up to $13 \mathrm{~mol} \%$ using solid state processes. Moreover, in a thermal barrier coating, the composition of the mixed zone of the thermally grown oxide and the ceramic top coat can delaminate when the interfaces are not compatible [28]. The new composition of $\mathrm{Dy}_{2} \mathrm{O}_{3}-\mathrm{Y}_{2} \mathrm{O}_{2}$ co-doped $\mathrm{ZrO}_{2}$ exhibited promising properties as ceramic thermal barrier materials for gas turbines in aero engines.

\section{Conclusions}

In conclusion, Dy ${ }_{0.25} \mathrm{Y}_{0.25} \mathrm{Zr}_{0.5} \mathrm{O}_{1.75}$ and $\mathrm{Dy}_{0.5} \mathrm{Zr}_{0.5} \mathrm{O}_{1.75}$ produced pure cubic fluorite phase, while Dy ${ }_{0.06} \mathrm{Y}_{0.072} \mathrm{Zr}_{0.868} \mathrm{O}_{1.934}$ and $\mathrm{Dy}_{0.02} \mathrm{Y}_{0.075} \mathrm{Zr}_{0.905} \mathrm{O}_{1.953}$ consisted of tetragonal and cubic phases. $\mathrm{Dy}_{2} \mathrm{O}_{3^{-}}$ 
$\mathrm{Y}_{2} \mathrm{O}_{3}$ co-doped $\mathrm{ZrO}_{2}$ exhibited lower thermal conductivity and higher coefficient of thermal expansion as compared with 4YSZ. Dy ${ }_{0.06} \mathrm{Y}_{0.072} \mathrm{Zr}_{0.868} \mathrm{O}_{1.934}$ produced the lowest thermal conductivity and relatively higher CTE amongst the other chemical compositions. The presence of $\mathrm{Dy}^{3+}$ in the zirconia lattice creates lattice strain and oxygen vacancies which are strong phonon scattering points and weaken the chemical bonding. The thermochemical compatibility between the $\mathrm{Al}_{2} \mathrm{O}_{3}$ and the $\mathrm{Dy}_{2} \mathrm{O}_{3}-\mathrm{Y}_{2} \mathrm{O}_{3}$ co-doped $\mathrm{ZrO}_{2}$ has been controlled by the content of the rare earth oxides. $\mathrm{Dy}_{0.25} \mathrm{Y}_{0.25} \mathrm{Zr}_{0.5} \mathrm{O}_{1.75}$ can react with $\mathrm{Al}_{2} \mathrm{O}_{3}$ to form $\mathrm{YAlO}_{3}$ and $\mathrm{Dy}_{3} \mathrm{Al}_{2}\left(\mathrm{AlO}_{4}\right)_{3} ; \mathrm{Dy}_{0.06} \mathrm{Y}_{0.072} \mathrm{Zr}_{0.868} \mathrm{O}_{1.934}$ is compatible with $\mathrm{Al}_{2} \mathrm{O}_{3}$.

\section{Acknowledgements}

One of the authors, Liu Qu would like to acknowledge the Dean of Engineering Research Scholarship for International Excellence, the University of Nottingham

\section{References}

[1] N.P. Padture, M. Gell, E.H. Jordan, Thermal barrier coatings for gas-turbine engine applications, Science 296 (Journal Article) (2002) 280-284.

[2] U. Schulz, K. Fritscher, M. Peters, Thermocyclic behavior of variously stabilized EB-PVD thermal barrier coatings, Journal of Engineering for Gas Turbines and Power 119 (4) (1997) 917921.

[3] X. Cao, R. Vassen, W. Fischer, F. Tietz, W. Jungen, D. Stöver, Lanthanum-cerium oxide as a thermal-barrier-coating material for high-temperature applications, Advanced Materials 15 (17) (2003) 1438-1442.

[4] W. Ma, D. Mack, J. Malzbender, R. Vaßen, D. Stöver, $\mathrm{Yb}_{2} \mathrm{O}_{3}$ and $\mathrm{Gd}_{2} \mathrm{O}_{3}$ doped strontium zirconate for thermal barrier coatings, Journal of the European Ceramic Society 28 (16) (2008) 3071-3081.

[5] H. Zhang, K. Sun, Q. Xu, F. Wang, L. Liu, Thermal conductivity of $\left(\mathrm{Sm}_{1-\mathrm{x}} \mathrm{La}_{\mathrm{x}}\right)_{2} \mathrm{Zr}_{2} \mathrm{O}_{7}(\mathrm{x}=0,0.25$, $0.5,0.75$ and 1) oxides for advanced thermal barrier coatings, Journal of Rare Earths 27 (2) (2009) 222-226.

[6] Z.G. Liu, J.H. Ouyang, Y. Zhou, J. Li, X.L. Xia, Influence of ytterbium- and samarium-oxides codoping on structure and thermal conductivity of zirconate ceramics, Journal of the European Ceramic Society 29 (4) (2009) 647-652.

[7] X. Qiang, P. Wei, W. Jingdong, Q. Longhao, M. Hezhuo, K. Mori, T. Torigoe, Preparation and thermophysical properties of $\mathrm{Dy}_{2} \mathrm{Zr}_{2} \mathrm{O}_{7}$ ceramic for thermal barrier coatings, Materials Letters 59 (22) (2005) 2804-2807.

[8] C. Wang, Experimental and computational phase studies of the $\mathrm{ZrO}_{2}$-based systems for thermal barrier coatings, in, Vol. Doctor of Philosophy, Stuttgart University, 2006.

[9] J.R.V. Garcia, T. Goto, Thermal barrier coatings produced by chemical vapor deposition, Science and Technology of Advanced Materials 4 (Journal Article) (2003) 397-402.

[10] J.D. Vyas, K.L. Choy, Structural characterisation of thermal barrier coatings deposited using electrostatic spray assisted vapour deposition method, Materials Science and Engineering: A 277 (1-2) (2000) 206-212.

[11] S. Farhikhteh, A. Maghsoudipour, B. Raissi, Synthesis of nanocrystalline YSZ $\left(\mathrm{ZrO}_{2}-8 \mathrm{Y}_{2} \mathrm{O}_{3}\right)$ powder by polymerized complex method, Journal of Alloys and Compounds 491 (1-2) (2010) 402-405.

[12] L. Wang, Y. Wang, X.G. Sun, J.Q. He, Z.Y. Pan, C.H. Wang, A novel structure design towards extremely low thermal conductivity for thermal barrier coatings - Experimental and mathematical study, Materials \& Design 35 (0) (2012) 505-517. 
[13] R. Chaim, Activation energy and grain growth in nanocrystalline Y-TZP ceramics, Materials Science and Engineering: A 486 (1-2) (2008) 439-446.

[14] U. Brossmann, R. Würschum, U. Södervall, H.-E. Schaefer, Oxygen diffusion in ultrafine grained monoclinic $\mathrm{ZrO}_{2}$, J. Appl. Phys. 85 (11) (1999) 7646-7654.

[15] F. Yang, Electrical and thermal properties of yttria-stabilised zirconia (YSZ)-based ceramic materials, in: Faculty of Engineering and Physical Science, Vol. Doctor of Philosophy, The University of Manchester, 2011, pp. 173.

[16] B.P. Mandal, A.K. Tyagi, Pyrochlores: potential multifunctional materials, BARC NEWSLETTER (313) (2010) 6-13.

[17] F.N. Sayed, V. Grover, K. Bhattacharyya, D. Jain, A. Arya, C.G.S. Pillai, A.K. Tyagi, $\mathrm{Sm}_{2-}$ ${ }_{x} \mathrm{Dy}_{\mathrm{x}} \mathrm{Zr}_{2} \mathrm{O}_{7}$ pyrochlores: probing order-disorder dynamics and multifunctionality, Inorganic Chemistry 50 (2011) 2354-2365.

[18] Z. Qu, C. Wan, W. Pan, Thermal expansion and defect chemistry of MgO-doped $\mathrm{Sm}_{2} \mathrm{Zr}_{2} \mathrm{O}_{7}$, Chemistry of Materials 19 (2007) 4813-4918.

[19] S. Heiroth, R. Frison, J.L.M. Rupp, T. Lippert, E.J. Barthazy Meier, E. Müller Gubler, M. Döbeli, K. Conder, A. Wokaun, L.J. Gauckler, Crystallization and grain growth characteristics of yttriastabilized zirconia thin films grown by pulsed laser deposition, Solid State Ionics 191 (1) (2011) 12-23.

[20] L. Jin, Q. Yu, L. Ni, C. Zhou, Micrustructure and thermal properties of nanostructured 8 wt.\% $\mathrm{CeO}_{2}$ doped YSZ coatings prepared by atmospheric plasma spraying, Journal of Thermal Spray Technology 21 (5) (2012) 928-934.

[21] P.G. Klemens, Phonon scattering by oxygen vacancies in ceramics, Physica B: Condensed Matter 263-264 (0) (1999) 102-104.

[22] X. Xia, R. Oldman, R. Catlow, Computational Modeling Study of Bulk and Surface of YttriaStabilized Cubic Zirconia, Chemistry of Materials 21 (15) (2009) 3576-3585.

[23] F. Qun-bo, Z. Feng, W. Fu-chi, W. Lu, Molecular dynamics calculation of thermal expansion coefficient of a series of rare-earth zirconates, Computational Materials Science 46 (3) (2009) 716-719.

[24] M.O. Zacate, L. Minervini, D.J. Bradfield, R.W. Grimes, K.E. Sickafus, Defect cluster formation in $\mathrm{M}_{2} \mathrm{O}_{3}$-doped cubic $\mathrm{ZrO}_{2}$, Solid State Ionics 128 (1-4) (2000) 243-254.

[25] R. Gilissen, A.J. Flipot, R. Lecocq, Tentative $\mathrm{Dy}_{2} \mathrm{O}_{3}-\mathrm{Al}_{2} \mathrm{O}_{3}$ phase diagram and preparation of pure single-phase Dy aluminates, Journal of the American Ceramic Society 57 (8) (1974) 274.

[26] A.R. West, Solid state chemistry and its applications, John Wiley \& Sons Ltd., 1985.

[27] G. Falkenberg, U. Krell, J.R. Schneider, HASYLAB Annual Report 2003, in: L. Vasylechko, A. Matkovskii, A. Senyshyn, D. Savytskii, M. Knapp, C. Bähtz (Eds.) Crystal structure and thermal expansion of orthorhombic perovskite-type RE aluminates, 2003.

[28] H. Zhao, M.R. Begley, A. Heuer, R. Sharghi-Moshtaghin, H.N.G. Wadley, Reaction, transformation and delamination of samarium zirconate thermal barrier coatings, Surface and Coatings Technology 205 (19) (2011) 4355-4365. 